Griffith, B. and Chen, Q. 2003. "A momentum-zonal model for predicting zone airflow and temperature distributions to enhance building load and energy simulations,” HVAC\&R Research, 9(3), 309-325.

\title{
A Momentum-Zonal Model for Predicting Zone Airflow and Temperature Distributions to Enhance Building Load and Energy Simulations
}

Brent Griffith
Member ASHRAE
Qingyan (Yan) Chen; Ph.D. ${ }^{1}$

Member ASHRAE

\begin{abstract}
Building load and energy simulation programs based on the complete-mixing air model fail to consider the impact of non-uniform air temperature distributions. A momentum-zonal model based on the Eüler equation has been developed to enhance building load and energy simulations by predicting indoor airflows and temperatures. This paper shows some validation exercises by comparing model results to measurements and computational fluid dynamics. The model was found to predict thermal stratification conditions reasonably well and to err on the side of complete mixing. The model has been coupled to the heat balance model and tested on load calculations. Results for cooling and heating loads are compared to the traditional completemixing model with minor affects on total load but important differences in air system flow rate and control options. Total computation times for load calculations were two orders of magnitude higher using the momentum-zonal model compared to traditional complete-mixing.
\end{abstract}

\section{NOMENCLATURE}

\begin{tabular}{|c|c|c|}
\hline A & {$\left[\mathrm{m}^{2}\right]$} & surface area \\
\hline$c_{p}$ & {$[\mathrm{~J} / \mathrm{kg} \cdot \mathrm{K}]$} & air specific heat at constant pressure \\
\hline g & {$\left[\mathrm{m} / \mathrm{s}^{2}\right]$} & gravity force vector \\
\hline$h_{c}$ & {$\left[\mathrm{~W} / \mathrm{m}^{2} \cdot \mathrm{K}\right]$} & surface convection heat transfer (film) coefficient \\
\hline$\dot{m}$ & {$[\mathrm{~kg} / \mathrm{s}]$} & mass flow rate \\
\hline $\mathrm{P}$ & {$[\mathrm{Pa}]$} & air pressure \\
\hline$\dot{Q}_{\text {conv }, s}$ & {$[\mathrm{~W}]$} & convection heat gain from internal sources \\
\hline$\dot{Q}_{s y s}$ & {$[\mathrm{~W}]$} & air system sensible heat load, negative indicates cooling \\
\hline$T_{a_{i}}$ & {$\left[{ }^{\circ} \mathrm{C}, \mathrm{K}\right]$} & air drybulb temperature for near-surface \\
\hline$T_{a, i}$ & {$\left[{ }^{\circ} \mathrm{C}\right]$} & cell air temperature \\
\hline$T_{r e f}$ & {$\left[{ }^{0} \mathrm{C}\right]$} & reference temperature somewhere in the domain \\
\hline$T_{s}$ & {$\left[{ }^{\circ} \mathrm{C}, \mathrm{K}\right]$} & surface temperature at inside face \\
\hline$T_{\text {supply }}$ & {$\left[{ }^{\circ} \mathrm{C}, \mathrm{K}\right]$} & dry-bulb temperature at air supply \\
\hline $\mathbf{V}$ & {$[\mathrm{m} / \mathrm{s}]$} & velocity vector \\
\hline$\beta$ & {$[1 / \mathrm{K}]$} & expansion coefficient of air \\
\hline$\nabla$ & {$[-]$} & differential operator "del" \\
\hline$\rho$ & {$\left[\mathrm{kg} / \mathrm{m}^{3}\right]$} & air density \\
\hline
\end{tabular}

\footnotetext{
${ }^{1}$ Brent Griffith is a Senior Engineer at the Center for Buildings and Thermal Systems, National Renewable Energy Laboratory, Golden, CO and Qingyan (Yan) Chen is a Professor of Mechanical Engineering at Ray W. Herrick Laboratories, School of Mechanical Engineering, Purdue University, West Lafayette, IN.
} 


\section{INTRODUCTION}

Building design affects airflow within building spaces with important consequences for indoor air quality, thermal comfort, and energy efficiency. Airflow models provide methods of predicting temperature and movement of air within a room. As with any modeling effort, the aim is to find a balance between model complexity and capturing enough of the physics. For building load and energy calculations, air models are needed to determine surface heat transfer conditions and HVAC system return air temperatures so that predictions are fair and reasonable for different envelope and equipment designs, operating conditions, and climates. Three-dimensional fluid flow models can be quite complex and require too much computing time or lack suitable robustness for routine building simulation. However, airflow involves complex phenomena and capturing effects in a general manner can be overly difficult for the simplest models.

A large variety of room airflow modeling techniques have been developed and applied to building problems over the past 30 years including: complete-mixing, nodal-network models, zonal models, and computational fluid dynamics (CFD). Figure 1 diagrams these classes of air models.

The complete-mixing model has been used for load and energy calculations for some thirty years. The application of a single control volume with a uniform zone air temperature at any point in time is reasonable for typical forced air system configurations where relatively good mixing is a design intent. However there are concerns that it might be deficient when the air system design or natural buoyancy-driven flow of warm/cold air causes non-uniform zone air temperatures.

Nodal-network models treat the building room air as an idealized network of nodes connected with prescribed flow rates and allow calculating air temperatures at each node. Models have been developed for specific situations such as convective heating, lighting fixtures, displacement ventilation, and natural ventilation but have not been shown to be suitably general for broad application.

In this paper, "zonal" models refer to air models that use a three-dimensional grid to divide the entire room into a system of control volumes, or cells. Care should be taken to avoid confusing zone with zonal, where the former refers to traditional building zoning and the later refers to one category of room airflow models. In zonal modeling, balance equations are formulated for each cell that attempt to account for how flow rates might change based on temperature differences, length scales, and initial momentum. Some of the cells are associated with a special driving mechanism because walls, jets or plumes directly affect them. These are termed special cells. Special cells have "flow laws" associated with them which are generally simple correlations chosen from the engineering literature or generated by the model developers so that model predictions match experiments. Pressure-zonal models use Bernoulli relations to compute mass flows in so-called drift cells that lie between special cells. Pressure-zonal models are considered in more detail since there is a perception that they offer three-dimensional airflow models suitable for building load/energy simulation.

Inard et al. (1996) present a three-dimensional pressure-zonal model with special cells for walls, jets and plumes. The mass flow into or out of a cell, is modeled using pressure drop relations that use a discharge coefficient, $C_{d}$, usually taken as around 0.8. Wurtz et. al. (1999) adds linear flow distributions at vertical cell faces rather than uniform, "top-hat" distributions. This approach is also used by Haghigat et al. (2001). Recent developments to automate the process of applying special laws to cells that drive the flow have been reported by Gagneau and Allard (2001) and Deque et al. (2001). Wurtz et al (2001) present linearized and sequential 
formulations of pressure-zonal models. Clearly such research has demonstrated that it is possible to use pressure-zonal models in load/energy calculation programs.

However, applying pressure-zonal models to general building simulation is not straightforward because of the complexity of special laws and non-physical treatment of flows. Characteristics of the flow, such as the type of jet, direction of plumes, depth of wall influence, need already be known prior to the simulation so that special cells can be set up appropriately. Thus, expertise is needed by the user, or as an expert system in the program, to describe the thermal zone. A given cell may also be affected by more than one driving condition and be very difficult for special flow laws to model. The overall complexity involved in deciding between the when, where, and what of applying flow laws could also raise pragmatic difficulties in forming consensus-based standard calculation procedures. Axely (2001) points out that in aggregate the models predict non-physical and grid-dependent pressure drops. The models neglect momentum (by assuming that velocities are so low) thereby discarding considerable flow information. These concerns lead to incorporating more physics into such a model so that each cell can be treated in the same manner without special cell laws.

Computational Fluid Dynamics (CFD) offers such capabilities and has long been applied to buildings. Most CFD predicts mean flow conditions using the Reynolds-Average Navier Stokes (RANS) equation models, such as zero-equation model (e.g. Prandtl mixing length model), one-equation model (e.g. k model), two-equation model (e.g. k- $\varepsilon$ model), and multiple equation models. CFD is used for HVAC system design and predicting comfort and/or air quality parameters. In the context of building energy and load calculations, CFD has been tightly coupled to several building load and energy simulation programs (Negaro et. al. 1995), Beausoleil-Morrison 2000, Chen et al. 1999, Chen and Zhai 2002). Because of the severe computing times, all of these efforts implemented simplified Prandtl-mixing-length turbulence models to improve speed. However, fine-grid descritization is needed to take advantage of turbulence and diffusion modeling making accurate CFD computationally expensive.

This paper presents a model that addresses the computing costs of CFD and physicsdeficiencies of pressure-zonal models. The model is termed "momentum-zonal" because it balances/conserves linear momentum (in addition to mass and energy) where momentum of the fluid in a control volume is the integral of momentum per unit volume $(\rho \mathbf{V})$. This model grew out of a need for a fast, three-dimensional model to use in testing code for a coupling framework developed for ASHRAE Research Project 1222 (Chen and Griffith 2002). This project coupled air models to load/energy routines that implement the Heat Balance Model (Pedersen 2001). This context also led to our focus on poorly-mixing flow situations and a primary goal of predicting temperature distributions, since temperature is a key parameter in load/energy calculations. The model is intended to be used with coarse grids for fast computation with resolution comparable to pressure-zonal models. This paper presents the model formulation, a summary of validation efforts, and example results when coupled to load routines.

\section{MODEL FORMULATION}

The momentum-zonal model solves the three-dimensional Eüler equation. Pressure-zonal models are often based on the Bernoulli equation that can be derived by integrating the Eüler equation. CFD models are often based on the Reynolds-Averaged Navier Stokes equation that can be reduced to the Eüler equation by neglecting terms with viscosity. In this way, the momentum-zonal model lies between pressure-zonal and CFD models. The steady-state Eüler equation for inviscid flow is, 


$$
(\mathbf{V} \cdot \nabla) \mathbf{V}=\frac{1}{\rho} \nabla P+\mathbf{g}
$$

The main assumption of inviscid flow is shared with pressure-zonal models, while the solution technique is shared with CFD. This assumption is justified in the following way. Turbulence can be common in room airflows and modeling the air as inviscid eliminates the viscosity terms used to apply turbulence models. The effective viscosity (dynamic viscosity plus turbulent viscosity) modifies the diffusion terms of the Navier-Stokes flow equations. Because the magnitude of the diffusion terms is lower than the convection terms, eliminating these terms leads to relatively minor errors $(<30 \%)$ for stratified, low-velocity room airflows. Although important physics that dampen flow are lost in the modeling, it is suggested that the error associated with neglecting viscosity/diffusion may be an acceptable considering the increased speed with which flow and temperature predictions can be computed. In addition, the study suggests using a coase model that would generate a considerable numerical diffusion. The numerical diffusion would somehow compensate the elimination of the effective viscosity. It is not necessary that the model completely resolves the flow field (as in CFD) but rather give a rough account of mean mass flows for the benefit of the energy balances (that provide temperatures). For building load/energy modeling what is needed is a coarse estimate of zone air temperatures and the fine-grid discretization required to accurately model diffusion terms may not be warranted. However, if the airflow has significant turbulence then it should mix rather well and the complete mixing model is likely to be reasonable for building load/energy simulation.

Figure 2 diagrams a differential element of the type used in calculus. The three components of velocity $\mathbf{V}$ are $u$ in $\mathbf{x}$-direction, $v$ in y-direction, and $w$ in z-direction. Writing the differential form of the Eüler equation for inviscid flow in Cartesian coordinates in threedimensions, along with conservations of energy and mass, forms a system of partial differential equations that are the basis of the momentum-zonal model.

$$
\begin{aligned}
u \frac{\partial u}{\partial x}+v \frac{\partial u}{\partial y}+w \frac{\partial u}{\partial z} & =-\frac{1}{\rho} \frac{\partial P}{\partial x} \\
u \frac{\partial v}{\partial x}+v \frac{\partial v}{\partial y}+w \frac{\partial v}{\partial z} & =-\frac{1}{\rho} \frac{\partial P}{\partial y} \\
u \frac{\partial w}{\partial x}+v \frac{\partial w}{\partial y}+w \frac{\partial w}{\partial z} & =-\frac{1}{\rho} \frac{\partial P}{\partial z}-\beta\left(T_{r e f}-T_{a_{i}}\right) g \\
u \frac{\partial T_{a_{i}}}{\partial x}+v \frac{\partial T_{a i}}{\partial y}+w \frac{\partial T_{a_{i}}}{\partial z} & =\frac{1}{c_{p}} \dot{Q}_{c o n v, s}+\frac{h_{c} A}{c_{p}}\left(T_{s}-T_{a_{i}}\right)+\dot{m}\left(T_{a i}-T_{\text {Supply }}\right) \\
\frac{\partial u}{\partial x}+\frac{\partial v}{\partial y}+\frac{\partial w}{\partial z} & =0
\end{aligned}
$$

This investigation solves the momentum-zonal model by using the numerical technique usually employed in CFD. The technique (Patankar 1980) includes:

- finite-volume numerical techniques with an iterative and sequential approach 
- temperature solved at cell center while velocities on cell surface using the staggered grid formulation

- convective transfer treated by using the upwind technique

- pressure forces arising from buoyancy using the Boussinesq approximation

- neglected contribution of normal diffusion in the formulation that may reduce computing costs and significant false numerical diffusion is expected with coarse grids

- various boundary conditions allowed and blockages inside the flow domain permitted

- SIMPLE (Semi-Implicit Method for Pressure-Linked Equations) algorithm

- tri-diagonal matrix techniques used to solve the recurrence situation through a series of one-dimensional sweeps

- "false time steps" and linear relaxation used to stabilize the numerical simulation More information on the momentum-zonal is available in the RP-1222 toolkit along with source code and programs that run it (Chen and Griffith 2002).

\section{VALIDATION OF THE MOMENTUM-ZONAL MODEL}

This section presents a summary of efforts to validate and characterize the behavior of the momentum-zonal model. Validation refers to comparing model predictions to measurements or more detailed models of a different type. Here the air model's ability to predict air temperaturesis tested by itself using prescribed surface temperatures and flow rates. In reality, the surface temperature may vary, but the use of the prescribed surface temperatures would not compromise the goal of validation. True validation of the coupled model is not possible because of a fundamental lack of suitable experimental data. The momentum-zonal model is capable of finegrid modeling as well as coarse-grid modeling envisaged for "zonal" models. Therefore models were run using both low resolution and moderate grid numbers. The finer grids allow representing room contents as blockages for flow. The grids used in this testing were intentionally somewhat crude in that the mesh was distributed uniformly rather than fine-tuned to obtain a custom grid that "fits" the problem. Better performance might be obtained with manual tuning of the grid, but we wanted to test the model in the context of very simple and coarse implementation. An important exception is the cells along the domain boundary that were all 0.2 $\mathrm{m}$ thick normal to the enclosure surfaces. This was done in order to model near-surface temperatures in a consistent manner for coupling to load/energy routines.

Three validation exercises, displacement ventilation, natural convection, and heating with a convective heater, are presented here, since they are very typical cases of non-uniform room airflow. Many important details of the cases are not included for the sake of brevity and the reader is encouraged to find more information in the appropriate references.

\section{Displacement Ventilation}

The validation exercises first used two displacement ventilation cases with measured data. The first case is described by Li et al. (1993) where it is referred to as "B3". The second case is described by Rees (1998) where it is referred to as "DV12." The momentum zonal model used measured surface temperatures, air system flow rate and inlet temperature, and convection heat gain from the internal source as its boundary conditions. The model for case B3 used a $9 \mathrm{x}$ $8 \times 8$ grid and for DV12 a $11 \times 7 \times 9$ grid. Figure 3 shows the results where data for a single vertical "column" of cells have been extracted to compare to measured distributions. Agreement is good for the case B3, yet for the case DV12 agreement is not very good for the lower portion of the room. However the errors are on the side of what the mixing model would predict. 
A third numerical validation exercise is presented to show the capability of the momentum-zonal model to predict the air temperatures with under-floor air distribution. A case was developed with an interior zone measuring $9.7 \mathrm{~m}$ long by $6.9 \mathrm{~m}$ wide by $2.74 \mathrm{~m}$ high. The zone has eight office cubicles laid out in an orthogonal pattern with four workstations in the long direction and two in the shorter direction. Each workspace includes a a person, a computer, and a swirl-type floor inlet diffuser at the entrance. The boundary conditions include assumed surface temperatures, convection heat gains from internal sources, and air system flow rates and inlet temperature. A commercial CFD program (CHAM 1999) was used to generate a numerical data set for reference using the diffuser modeling techniques investigated by Kobayashi (2001). The flow from one inlet is represented in great detail to capture the swirl initial momentum using a square block of eight patches. Each patch has a velocity vector arranged so that flow is directed at $60^{\circ}$ from horizontal and with the remaining horizontal component directed tangentially. The CFD simulation used a $72 \times 52 \times 28$ grid, standard k- $\varepsilon$ turbulence modeling, and required many hours of computing and considerable fine-tuning of input. A complete description of the cubicle partitions, people, computers, and tabletops was included in the CFD model.

Figure 4 shows the CFD results for temperature distributions compared to the momentum-zonal model. The momentum-zonal model used a $10 \times 8 \times 10$ grid and represented each diffuser with the same total mass flow but just one cell $(1.2 \mathrm{~m}$. by $1.1 \mathrm{~m}$.) and initial momentum of $2.0 \mathrm{~m} / \mathrm{s}$ upwards. Whereas the CFD model included blockages and careful representation of the office geometry, the momentum model did not represent blockages. The results show that the model can predict air temperature distributions characteristic in the room. The solution was obtained in about $24 \mathrm{~s}$.

\section{Natural Convection}

Zonal models can be applied to the problem of modeling natural convection in a sealed room. This has been called the "cold window problem" with the idea that under heating conditions, low performance windows get cold and may cause natural convection driven flow to develop in a room. Our study used the second case in Inard et al. (1996). The measurements were performed in a thermal test chamber of $3.1 \mathrm{~m}$ long x $3.1 \mathrm{~m}$ wide, and $2.5 \mathrm{~m}$ high (Allard et al. 1987). The apparatus attempts to achieve isothermal inside face wall temperatures. The enclosure surface temperature is around $27^{\circ} \mathrm{C}$ except the south wall at $16.9^{\circ} \mathrm{C}$ and north wall at $33.0^{\circ} \mathrm{C}$. Modeling boundary conditions include the measured surface temperatures of the six walls.

Figure 5 shows the results from the momentum model for air temperatures using two different grids and compared to measurement and CFD. Figure 6 shows the computed airflows for various grid resolutions along with the computation results by Inard (1996) and Lin (1999). The momentum-zonal model shows exaggerated buoyancy-driven flow and slightly errs on the side of mixing.

\section{Convective Heating}

The momentum-zonal model was further tested using the measured data from a full-scale environmental chamber with a baseboard heater (the "infiltration case" in Chen et al. 1999) as diagramed in Figure 7. In this test case, the baseboard heater drives most of the flow with a lowvelocity, large-area inlet air simulating infiltration $(3 \mathrm{ACH})$. The modeling boundary conditions included measured surface temperatures, air system flow rates and inlet temperature, and convection heat gain from the internal sources. 
Although experimental data are shown as contour plots, they were actually gathered from 5 poles along the mid-plane in the y-direction with 8 probes on each (in the vertical direction). Therefore the plots show measured data with considerable extrapolation between the poles. The measurements also gathered mean air velocities at six heights on the poles using omnidirectional anemometers; the highest velocities were near the inlet $(0.1 \mathrm{~m} / \mathrm{s})$ and near the ceiling in the half of the room closer to the heater $(0.16 \mathrm{~m} / \mathrm{s})$. All of the velocities at probe locations are within the uncertainty of the measurements. $\dot{Q}_{s y s}$ was determined experimentally from the inlet and outlet temperatures (measured with thermisters) and the air flow rate.

Table 1 presents a summary of the measured and simulated results for the case. The results are plotted in Figures 8 as temperature contour plots. Three different runs of the momentum-zonal model are shown corresponding to different options in using the program. Coarse grid and fine grid models were run in order to explore their effect on the predictions of the model. The coarse grid run in Figure 8 used $12 \times 7 \times 6$ or 504 cells. The finer grid runs in Figure 8 used $27 \times 22 \times 20$ or 11880 cells. For the coarse grid, heat sources that are close together are combined and no blockages are used. The two finer grids model each of the internal contents separately and in one case the contents are blockages and in the other case they do not block flow. Results are mixed, but the overall results indicate that the coarse-grid solution seems as useful as the fine-grid model. 
Table 1 Summary of the momentum-zonal model results for the case with a baseboard heater

\begin{tabular}{|c|c|c|c|c|}
\hline & $\begin{array}{c}\dot{Q}_{s y s} \\
{[\mathrm{~W}]}\end{array}$ & $\begin{array}{c}T_{\text {sysDiff }} \\
{\left[{ }^{\circ} \mathrm{C}\right]}\end{array}$ & $\begin{array}{c}T_{\text {leaving }} \\
{\left[{ }^{\circ} \mathrm{C}\right]}\end{array}$ & $\begin{array}{c}T_{\text {stat } D B} \\
{\left[{ }^{\circ} \mathrm{C}\right]}\end{array}$ \\
\hline Measured & 491 & 10.8 & 24.0 & 24.2 \\
\hline $\begin{array}{l}\text { Coarse-Grid }(504 \text { cells }) \\
\text { no blockages }\end{array}$ & 574 & 10.9 & 25.7 & 24.1 \\
\hline $\begin{array}{l}\text { Fine-Grid (11880 cells }) \\
\text { with blockages }\end{array}$ & 503 & 9.7 & 24.1 & 22.9 \\
\hline $\begin{array}{l}\text { Fine-Grid (11880 cells }) \\
\text { no blockages }\end{array}$ & 610 & 10.9 & 26.4 & 24.1 \\
\hline
\end{tabular}

\section{COUPLING THE MOMENTUM-ZONAL MODEL WITH BUILDING LOAD AND ENERGY SIMULATIONS}

The above validation shows that the momentum zonal model is able to predict indoor airflow and temperature distributions with reasonable accuracy. The model could be integrated with a building load and energy simulation model. Coupling enables considering the impact of non-uniform indoor air distribution on HVAC system design and operation as well as thermal comfort. In the context of load calculations, this investigation used the coupling framework developed by the authors (Chen and Griffith 2002) with the Heat Balance Model implemented by Pedersen et al. (2001). The complete-mixing model results are also presented in order to show how the solutions change when the heat balance model is enhanced by the momentum zonal model. With the coupling, the heat balance model can provide boundary conditions, such as room surface temperature, supply airflow rate, and supply air temperature to the momentumzonal model. On the other hand, the momentum-zonal model presents the non-uniform air temperature distribution of the room to improve the accuracy of the heat balance model. Therefore, the coupling is complementary between the two models. Although CFD models can be formulated such that surface convection heat transfer coefficients can be determined locally (from the turbulence modeling) the momentum-zonal model cannot predict these coefficients in the same manner requiring the use of fixed values or correlations that should be appropriate for modeling convection using near-surface air temperatures (see Chen and Griffith 2002).

This section demonstrates the capacity of the coupled program for two design cases: displacement ventilation in a medium-sized office building and convective heating in a room with a baseboard heater.

\section{Displacement Ventilation}

The displacement ventilation case is to determine the peak load and thermal comfort conditions at the summer design day in a medium-sized office building in Sacramento, CA. The study focused on an open-plan office for seven occupants that is $8 \mathrm{~m}$ long, $8 \mathrm{~m}$ wide, and $2.74 \mathrm{~m}$ high. The internal load schedules are patterned after energy modeling practice for a day-shift schedule with maximum loads of about $35 \mathrm{~W} / \mathrm{m}^{2}$ and splits of $50 \%$ convection and $50 \%$ radiation. The south wall is stone veneer on metal framing and was exposed to outside air. The west wall has stone on the lower portion and is entirely glazed above with low-shading- 
coefficient insulated glazing units. Other surfaces are interior partitions. Vertical surfaces were subdivided into four segments. Both the mixing and momentum models used default ASHRAE surface convection film coefficients of $4.68 \mathrm{~W} / \mathrm{m}^{2} \cdot \mathrm{K}$ for the vertical walls, $1.25 \mathrm{~W} / \mathrm{m}^{2} \cdot \mathrm{K}$ for the ceiling, and $4.37 \mathrm{~W} / \mathrm{m}^{2} \cdot \mathrm{K}$ for the floor.

Unlike the displacement ventilation cases discussed in the previous section, the Heat Balance Model provides the interior surface temperature for the momentum-zonal model during the simulation. Therefore, the prescribed wall surface temperatures, which are difficult to obtain in the design stage, are no longer necessary. Figure 9 shows computed results comparing the mixing model to the momentum model using a grid of 10x10x11 with non-blocking internal load objects. Supply air temperature is $17.2^{\circ} \mathrm{C}$ and room air set point is constant at $22.8^{\circ} \mathrm{C}$. The flow and temperature sections in Figure 9 are for a slice that includes the inlet. Mass flow rates have been converted to velocities. The mixing model computation took 5 seconds but the momentummodel took 29.25 minutes when completely using one $800 \mathrm{MHz}$ PC processor. The average time spent computing each of the 1,440 calls to the air model was 1.2 seconds.

\section{Convective Heating}

A second numerical exercise is presented to explore heating applications. The case with a baseboard heater discussed in the previous section was used as diagrammed in Figure 7. This case adds mythical wall constructions and cold outdoor conditions that allow us to explore the capacity of the two-model coupling. The study used a steady outdoor air temperature of $-26.5^{\circ} \mathrm{C}$ that corresponds to $99.6 \%$ heating design condition for Minneapolis, MN (ASHRAE 2001). The wall constructions and other model inputs are documented detail in the ASHRAE final report for RP-1222 (Chen and Griffith 2002). The north wall and roof are exposed to the outdoors but have no glazing. The floor, south, west walls are interior partitions. The east wall has stone on the lower portion and is entirely glazed above with low shading coefficient insulated glazing units. Both the mixing and momentum models used default ASHRAE surface convection film coefficients of $4.68 \mathrm{~W} / \mathrm{m}^{2} \cdot \mathrm{K}$ for the vertical walls, $1.25 \mathrm{~W} / \mathrm{m}^{2} \cdot \mathrm{K}$ for the ceiling, and $4.37 \mathrm{~W} / \mathrm{m}^{2} \cdot \mathrm{K}$ for the floor. The results are given in Figure 10.

\section{DISCUSSION}

The validation results presented in this paper show that the momentum-model is able to compute air temperature distributions that agree reasonably well with measurements and CFD. We are mainly interested in computing temperature distributions in the context of load and energy calculations, but the flow field predictions appear reasonable for low mass flow rates. Non-physical or wildly varying temperatures were not encountered. In some cases there were significant temperature deviations $\left(>1.0^{\circ} \mathrm{C}\right)$ between the momentum model and measurements. The model under predicts vertical temperature gradients as shown in Figures 3, 4, and 5. However, it appears that the model tends to be conservative in terms of erring in the direction of the complete mixing model. This is likely because of numerical diffusion that is expected with use of coarse grids in such a numerical scheme or because of exaggerated flow rates simply create more mixing. The model appears useful for generating zone air temperature data at the coarse grid resolutions used in zonal modeling for certain types of room airflow situations. These situations are where thermal stratification is present and mean air velocities are low $(<0.2 \mathrm{~m} / \mathrm{s})$.

The model appears to over-predict buoyancy forces. Figure 6 shows that stronger flows

are predicted compared to two pressure-zonal models. Coarse grids appear to counteract the 
exaggerated plume problem probably because the momentum source/force is spread out over larger control volumes. The model does not handle turbulence and therefore allows some exaggerations where high velocity flows are being treated as laminar/inviscid. In reality, turbulence and mixing dampen out the strength of thermal plumes and this is not captured in the momentum model. While additional testing is required, it appears that neglecting blockages does not have a large affect on the temperature results for the small zones and contents in the test cases. Additional validation would be necessary before attempting to use the model for forced air systems with better mixing. The momentum-zonal model does not necessarily require the use of special cells but may over predict flows by not incorporating turbulence models and the empirical "knowledge" incorporated by the flow laws of special cells. While the model can consider internal blockages, results were just as good when treating internal objects as nonblocking volumetric heat sources.

Although true validation is difficult, the model produces reasonable results when coupled to load routines. There is a lack of suitable measured data for validating coupled air and surface modeling. Since the model's predictions of temperature are conservative compared to the mixing model it appears safe to use with load/energy routines. Before running in coupled mode, it was helpful to pre-run the air model in stand-alone operation in order to find relaxation parameters that provided relatively fast convergence through a process of trial and error. Changes in load calculation results using the momentum-zonal model were small but higher compared to complete-mixing model. For the cooling case, near-surface air temperatures used for surface convection calculations differed from the mixing model by $\pm 3.0^{\circ} \mathrm{C}$ leading to surface temperature deviations ranging from -1.2 to $0.5^{\circ} \mathrm{C}$. For the heating case, near-surface air temperatures differed by -1.0 to $2.0^{\circ} \mathrm{C}$ leading surface temperature deviations ranging from -0.5 to $1.0^{\circ} \mathrm{C}$. The changes in surface/air temperatures often even out which is why the completemixing model has served well for so long. However, for tall spaces, operative temperature control, and specialized analysis such as condensation resistance, the potentially more accurate predictions of surface temperature could be expected to be important.

The momentum model also provides predictions of air temperature at the point where air enters the air system return and at a designated thermostat location. The coupled model uses these values in determining air system flow rate and reductions of $25 \%$ have been observed (Chen and Griffith 2002). Another important advantage of the model is that since its numerical technique is similar to CFD moving to more detailed models will be facilitated as computing expenses fall.

\section{CONCLUSIONS}

A momentum-zonal model has been developed and coupled to load calculation routines from an ASHRAE toolkit. This model solves the steady Eüler equation using finite-volume numerical techniques. When used with coarse grids and Bousinessq buoyancy, the model is suggested as a "zonal" model that does not necessarily require special cells. The momentumzonal model was validated against measured data and found to predict temperatures reasonably well in situations where room air is stratified. The air temperature distributions obtained for use with load routines appear conservative in the sense that when in disagreement with measurements, the model tends to err on the side of the complete-mixing model. The momentum model can be used with coarse grids for buoyancy-dominated flow situations to produce data with resolution comparable to pressure-zonal models. At a minimum, the model allows testing a coupling framework for using zonal models with load routines. 
Results from cooling and heating load calculations using the complete mixing have been compared to those using the momentum model. The results for individual surfaces do vary with the additional modeling detail but in aggregate losses and gains often even out. Including such modeling should allow simulations to account for the higher heat extraction efficiency offered by designs that strive for stratified room air. The time required for computations increased by two orders of magnitude compared to the mixing model. Incorporating a three-dimensional, coarsegrid, air-modeling package into building simulation is feasible with contemporary computers but would require patient users.

\section{REFERENCES}

ASHRAE, 2001. 2001 ASHRAE Handbook Fundamentals. American Society of Heating, Refrigeration and Air-Conditioning Engineers, Inc. Atlanta, GA.

Axley, J.W. 2001. Surface-drag flow relations for zonal modeling. Building and Environment 36: 843-850.

Allard, F., Brau, J., Inard, C., and Pallier, J.M. 1987. Thermal experiments of full-scale dwellings cells in artificial conditions. Energy and Buildings 10(1): 49-58

Beausoleil-Morrison, I. 2000. The adaptive coupling of heat and air flow modeling within dynamic whole-building simulation. Ph.D. Thesis. University of Strathclyde, Glasgow U.K.

CHAM. 1999. PHOENICS Version 3.3. Concentration, Heat and Momentum Limited. London, UK.

Chen, Q., Glicksman, L., and Srebric, J. 1999. Simplified Methodology to Factor Room Air Movement and the Impact of Thermal Comfort into Design of Radiative, Convective and Hybrid Heating and Cooling Systems. Final Report for ASHRAE RP-927, Department of Architecture, Massachusetts Institute of Technology, Cambridge, MA.

Chen, Q. and Griffith, B. 2002. "Incorporating nodal and zonal room air models into building energy calculation procedures," Final Report for ASHRAE RP-1222, School of Mechanical Engineering, Purdue University, West Lafayette, IN.

Chen, Q. and Zhai, Z. 2002. "Coupling energy simulation and computational fluid dynamics programs," Final Report for Lawrence Berkeley National Laboratory, 116 pages, Department of Architecture, Massachusetts Institute of Technology, Cambridge, MA.

Deque, F., Evin, F. Wurtz, E., and Mora, L. 2001. Sim_Zonal: software evaluating indoor temperature distributions and air movements for rapid appraisals - first application to an cell. Proceedings of Seventh International IBPSA Conference, Rio de Janeiro, Brazil. 
Gagneau, S., and Allard, F. 2001. About the construction of autonomous zonal models. Energy and Buildings 33: $245-250$.

Haghighat, F., Lin, Y. and Megri, A.C. 2001. Development and validation of a zonal model POMA. Building and Environment 36:1039-1047

Inard, C., Bouia, H. and Dalicieux, P. 1996. Prediction of air temperature distribution in buildings with a zonal model. Energy and Buildings 24:125-132

Kobayashi, N. 2001. Floor-supply displacement ventilation system. M.Sc. Thesis, 174 pages, Department of Architecture, Massachusetts Institute of Technology, Cambridge, MA.

Li, Y., Sandberg, M. and Fuchs, L. 1993. Vertical temperature profiles in rooms ventilated by displacement: Full scale measurement and nodal modeling, Indoor Air 2:225-243.

Negrao, C., 1995. Conflation of Computational Fluid Dynamics and Building Thermal Simulation. Thesis. University of Strathclyde, Glasgow, UK.

Pedersen, C.O. 2001. Toolkit for building load calculations. American Society of Heating Refrigeration and Air-conditioning Engineers. Atlanta, GA

Patankar, S.V. 1980. Numerical Heat Transfer and Fluid Flow. Hemisphere Publishing Corporation, New York.

Rees, S.J. 1998. Modeling of displacement ventilation and chilled ceiling systems using nodal models. PhD Thesis, LoughBorough University. 1998.

Wurtz, E., Nataf, J-M, and Winkelmann, F. 1999. Two- and three-dimensional natural and mixed convection simulation using modular zonal models in buildings, Int. J. of Heat and Mass Transfer 42: 923-940.

Wurtz, E., Deque, F., Musy, M., and Mora, L. 2001. A thermal and airflow analysis tool using simplified models based on the zonal method. Proceedings of CLIMA $20007^{\text {th }}$ REHVA World Congress . Napoli, Italy. 


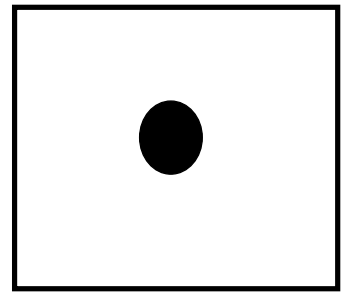

Complete-Mixingl

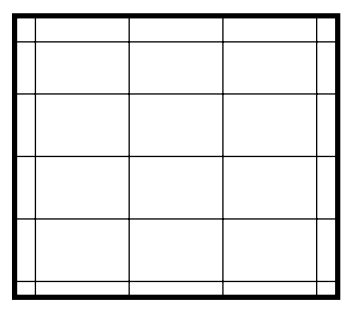

Zonal

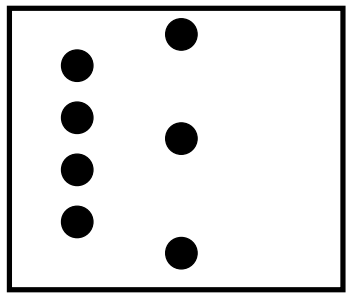

Nodal Network

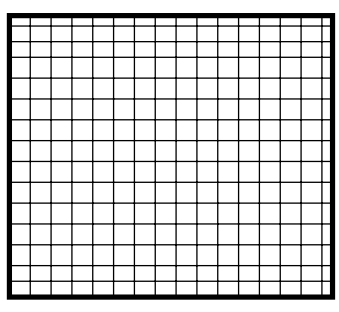

CFD

Figure 1 Classification of room air models 


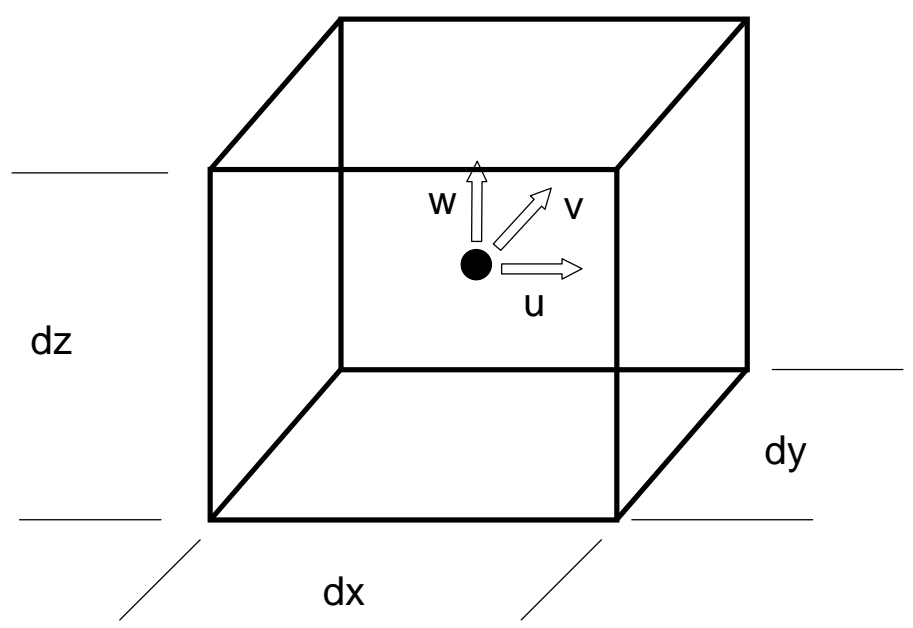

Figure 2 Differential element for room air 


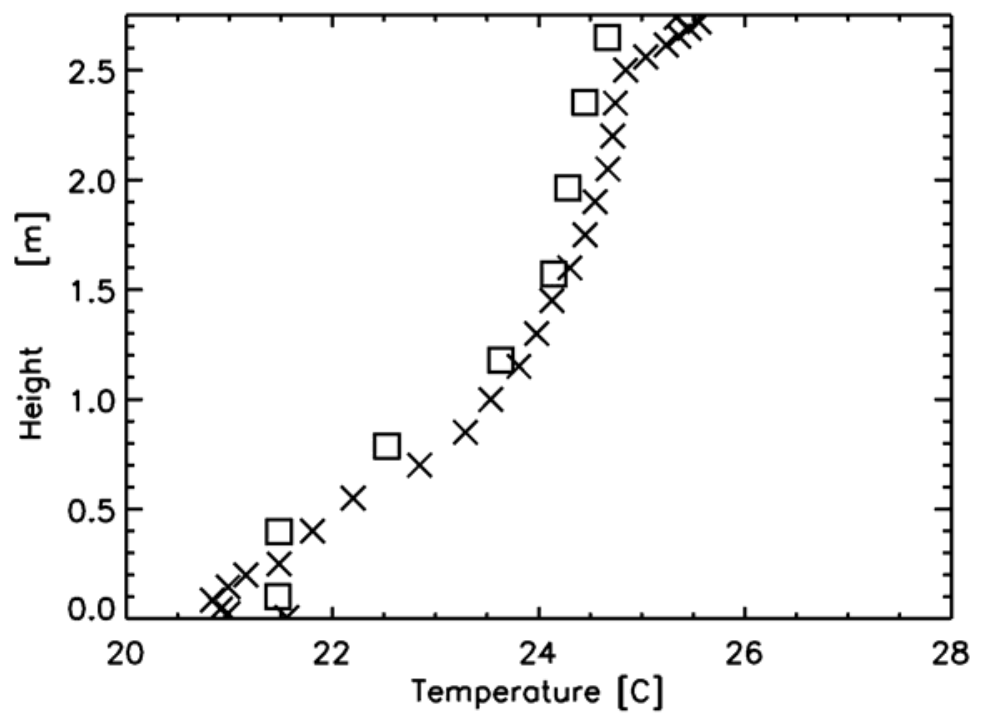

(a)

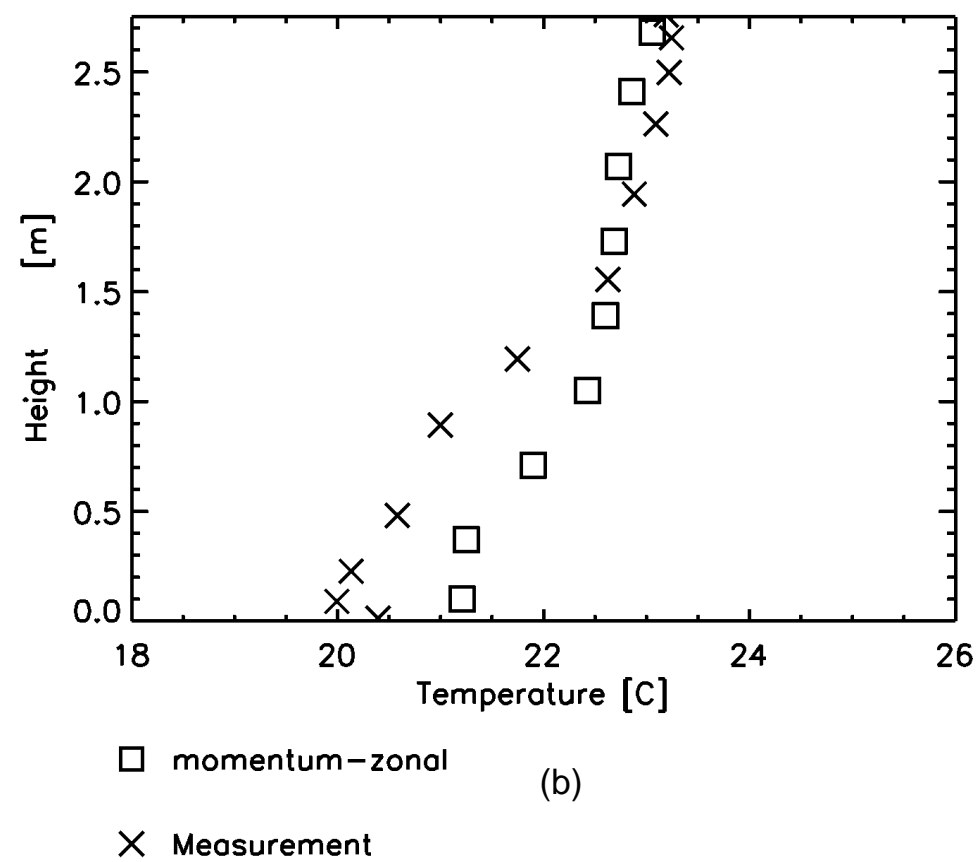

Figure 3 Air temperature results by using momentum zonal model (a) case B3(Li et al. 1993) and (b) case DV_12(Rees 1998) 


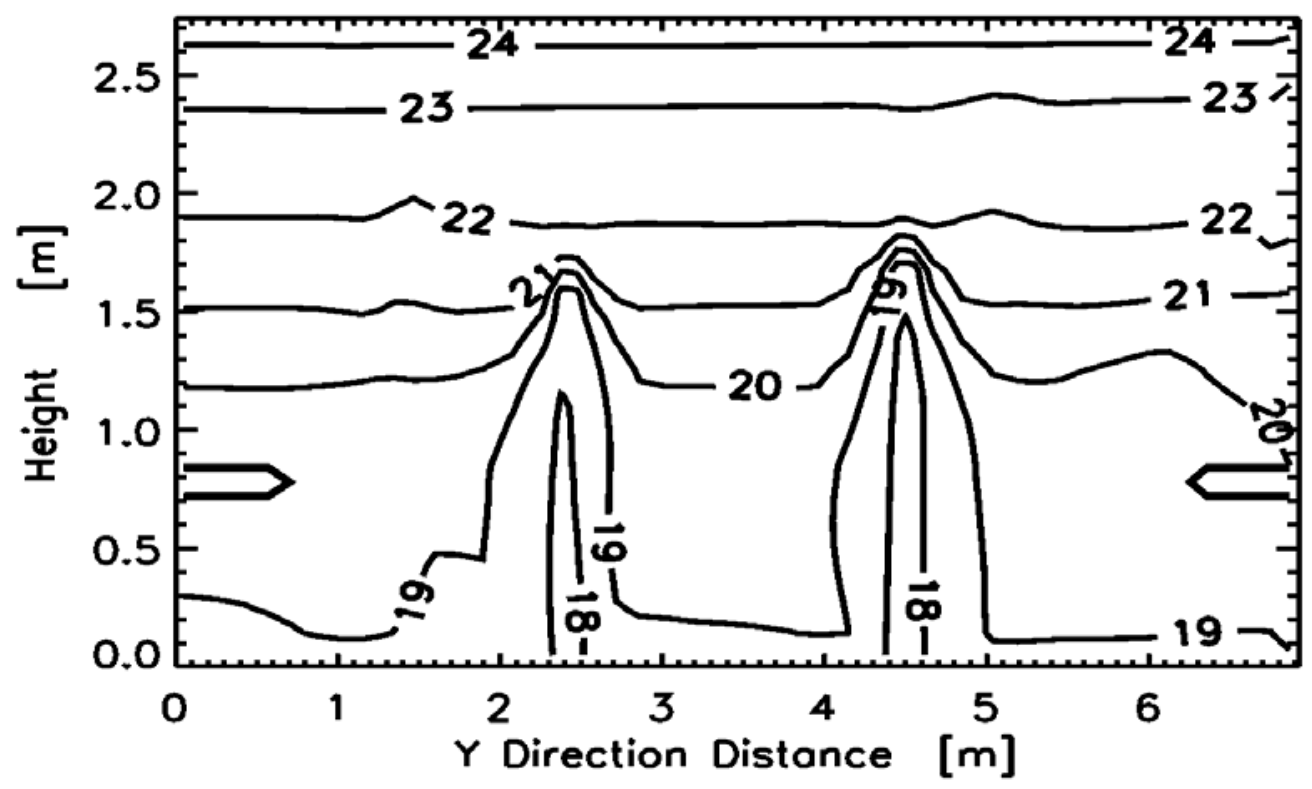

(a)

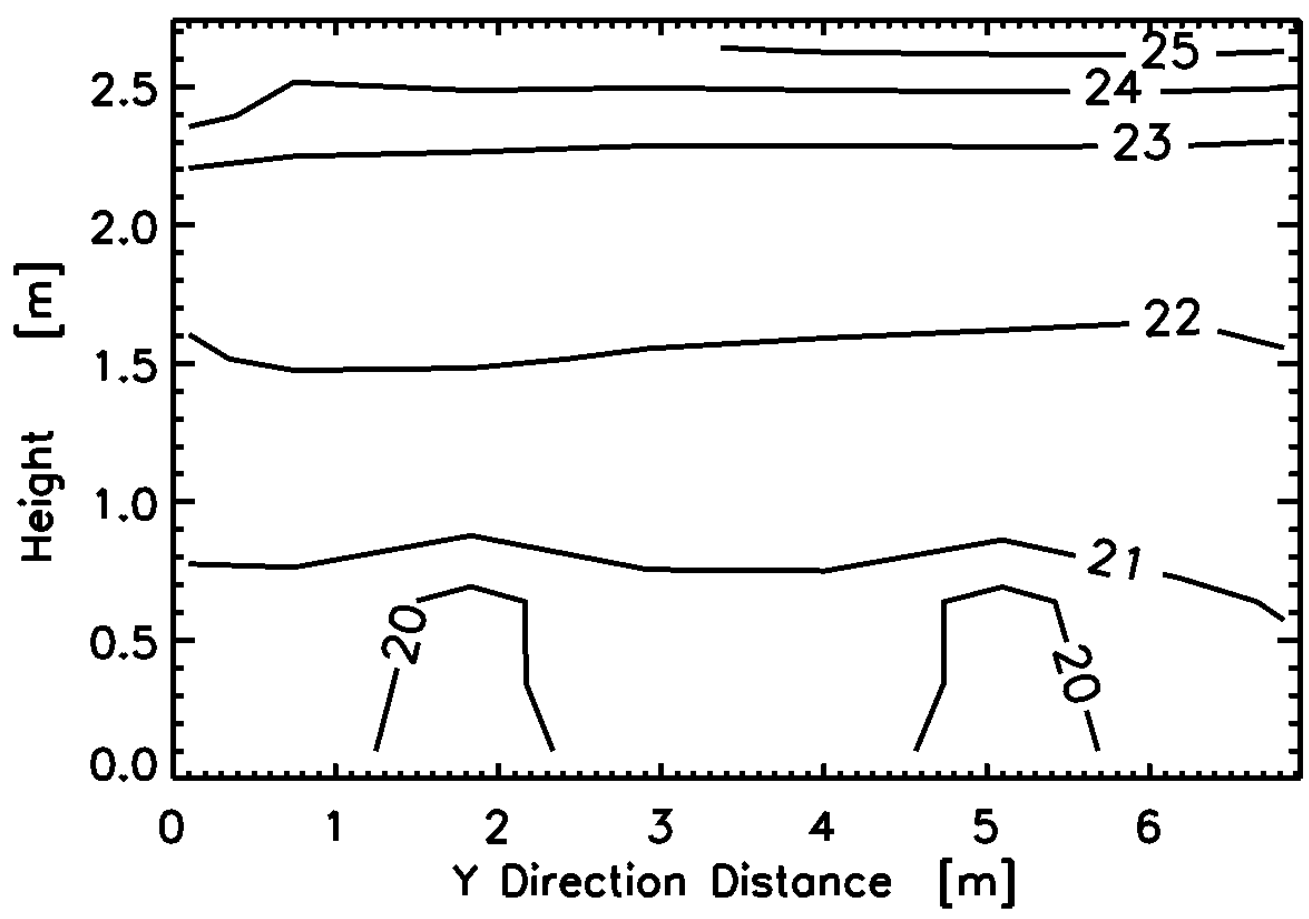

(b)

Figure 4 Air temperatures $\left({ }^{\circ} \mathrm{C}\right)$ distributions in cubicles with under-floor air distribution (a)CFD with the $k-\varepsilon$ model and a grid of $72 \times 52 \times 28$, (b) momentum-zonal model with a grid of $10 \times 8 \times 10$. 


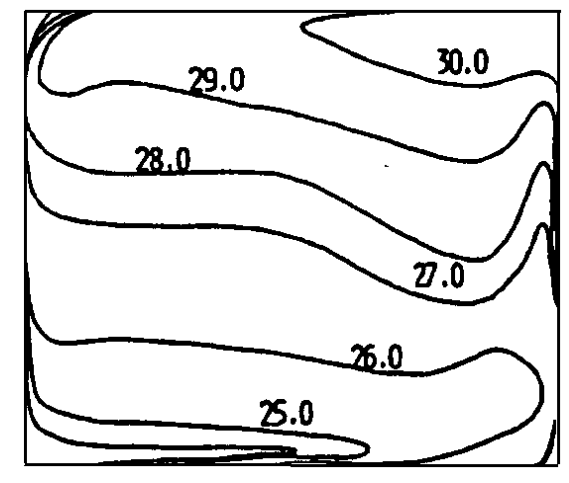

(a)

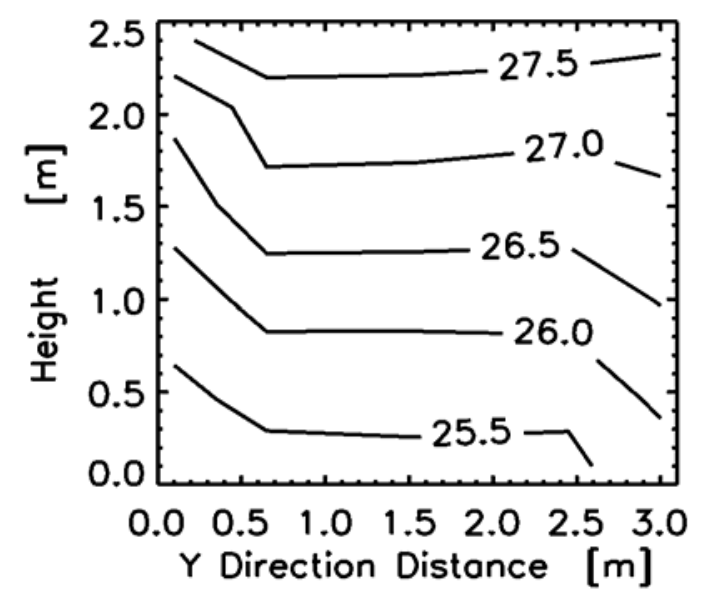

(c)

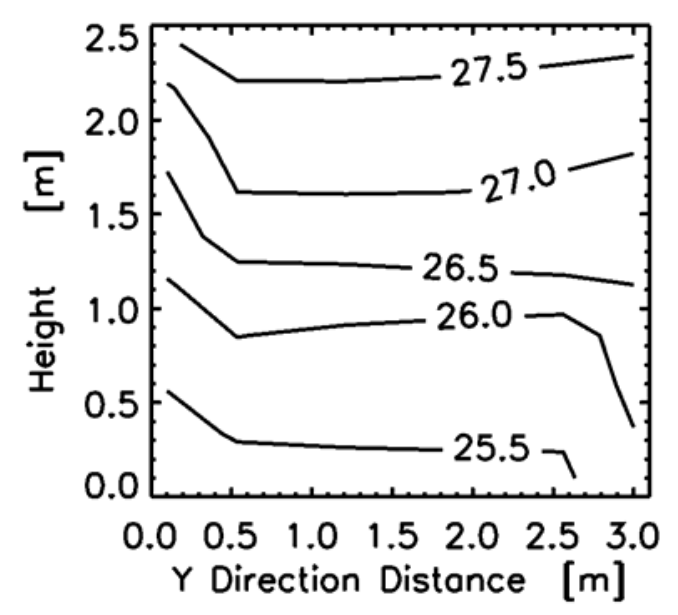

(b)

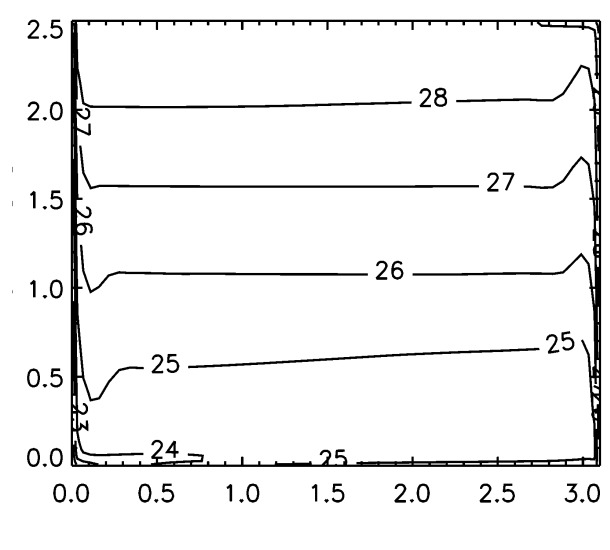

(d)

Figure 5 Air temperature distributions for the natural convection case (a) measurement (Inard et. al. 1996), (b) momentum-zonal model (2D-1x6x10), (c) momentum-zonal (3D-5x5x6), (d) $C F D$ 

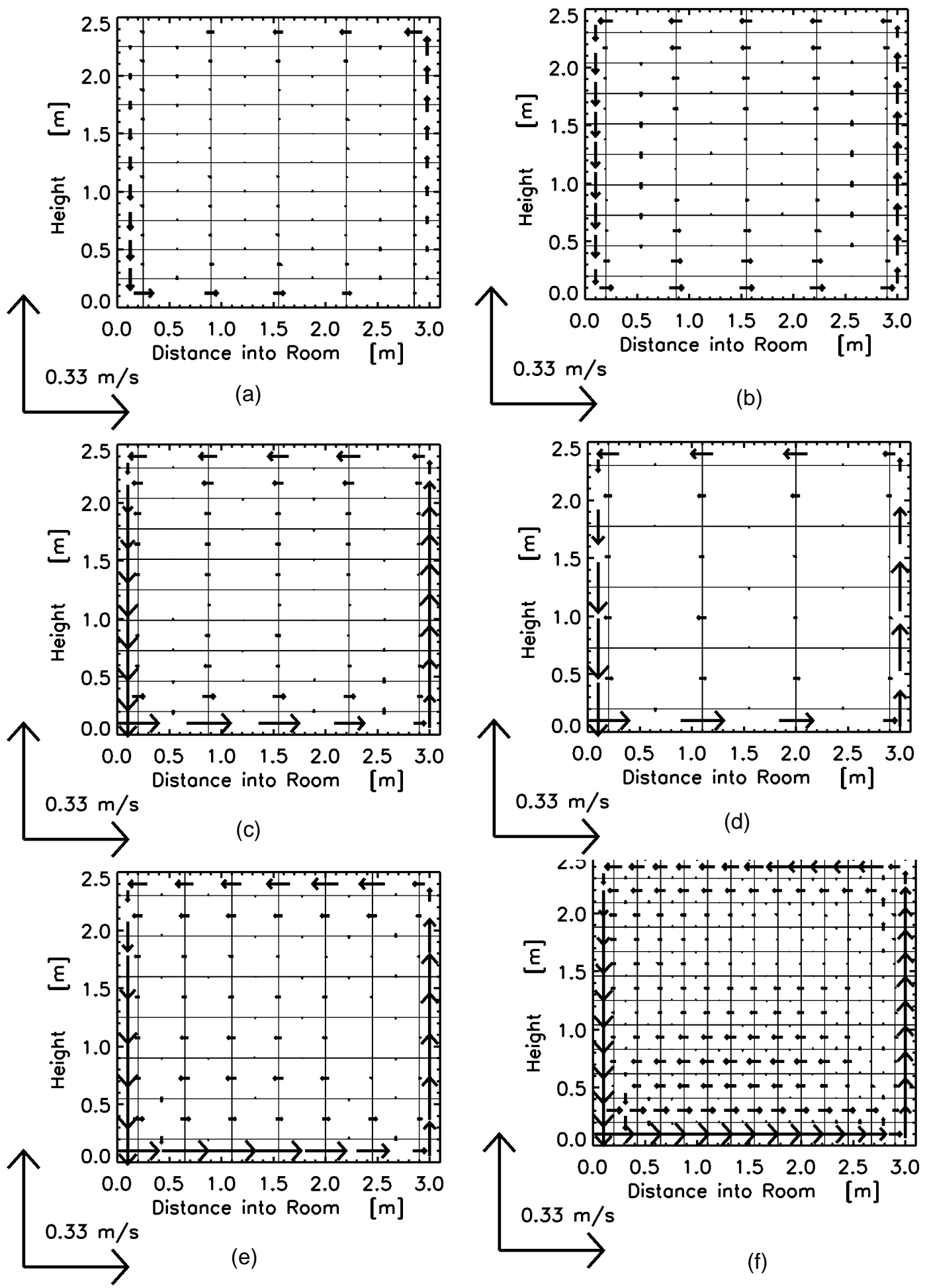

Figure 6 Airflow patterns for the natural convection case (a) pressure zonal model by Inard (1996) with 2D-1x6x10 grids), , (b) pressure zonal model by Haghighat et. al. (2001)) with 2D$1 \times 6 \times 10$ grids, (c) momentum-zonal model (2D-1x6x10), (d) momentum-zonal model with 3D$5 \times 5 \times 6$ grids, (e) momentum-zonal model with 3D-8x8x8 grids, (f) momentum-zonal model with $3 D-14 \times 14 \times 12$ grids 


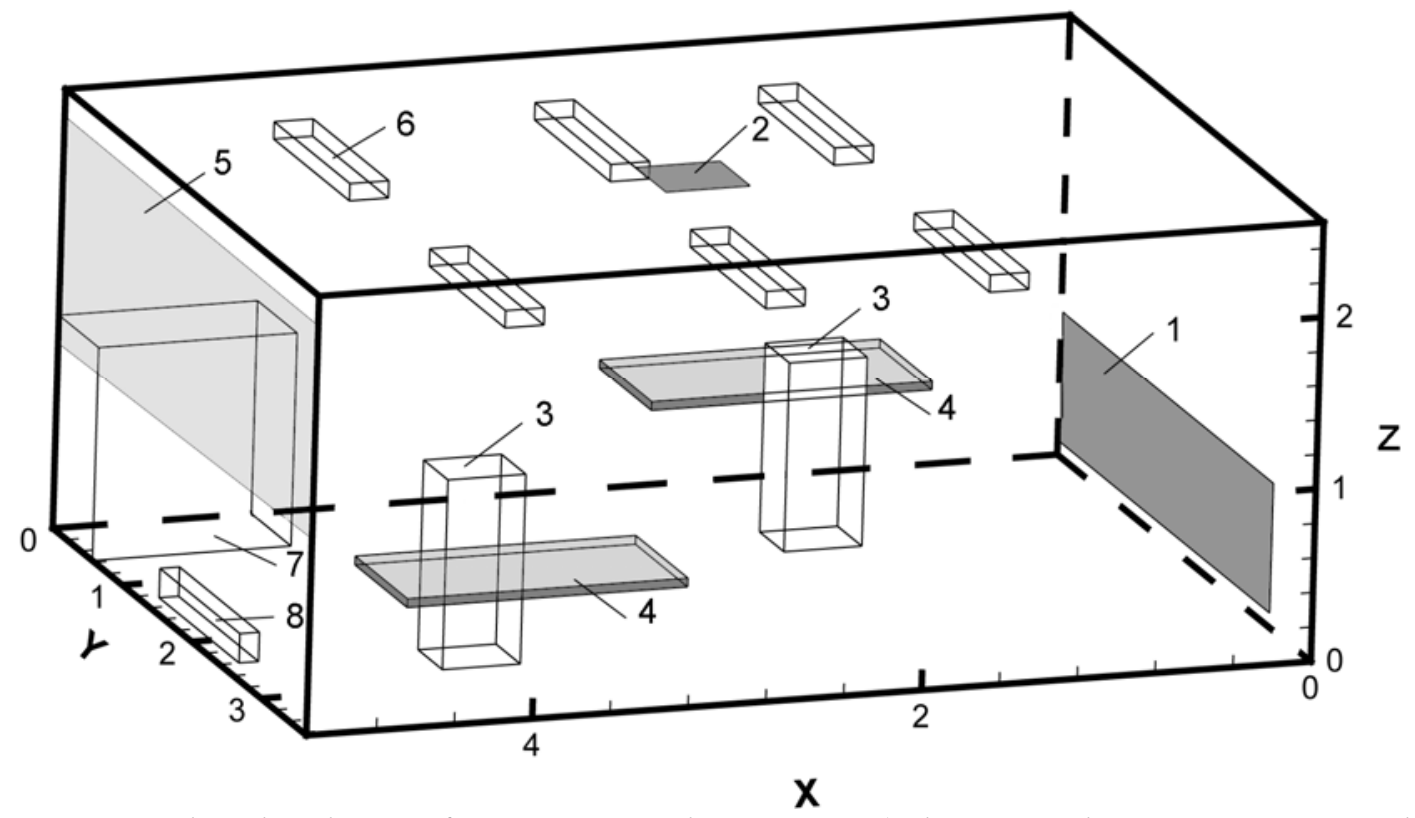

Figure 7 Test chamber layout for convective heater case(inlet -1 , outlet -2 , person -3 , table with computer-4, window -5, fluorescent lamps -6, cabinet -7, baseboard heater -8). 


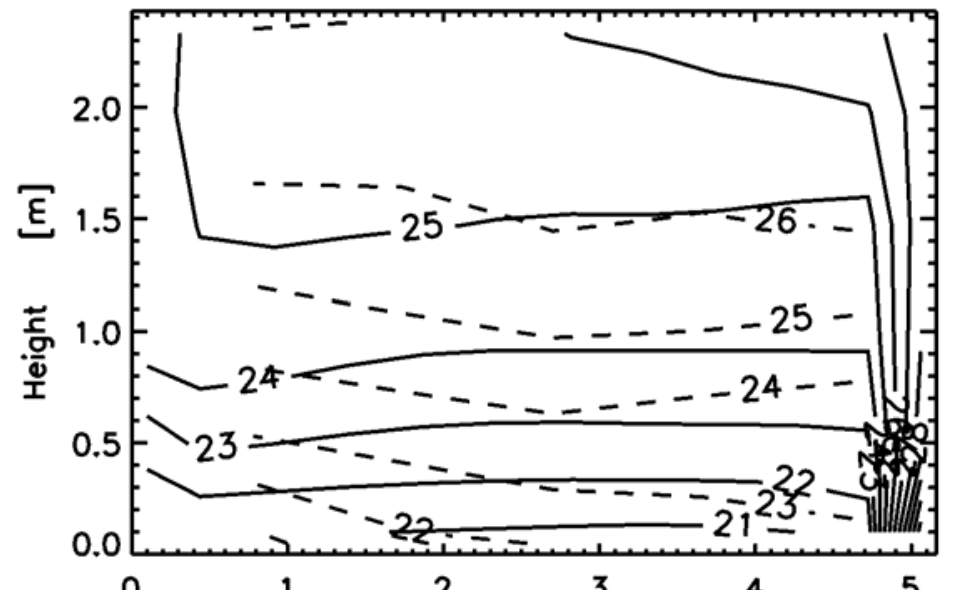

(a)

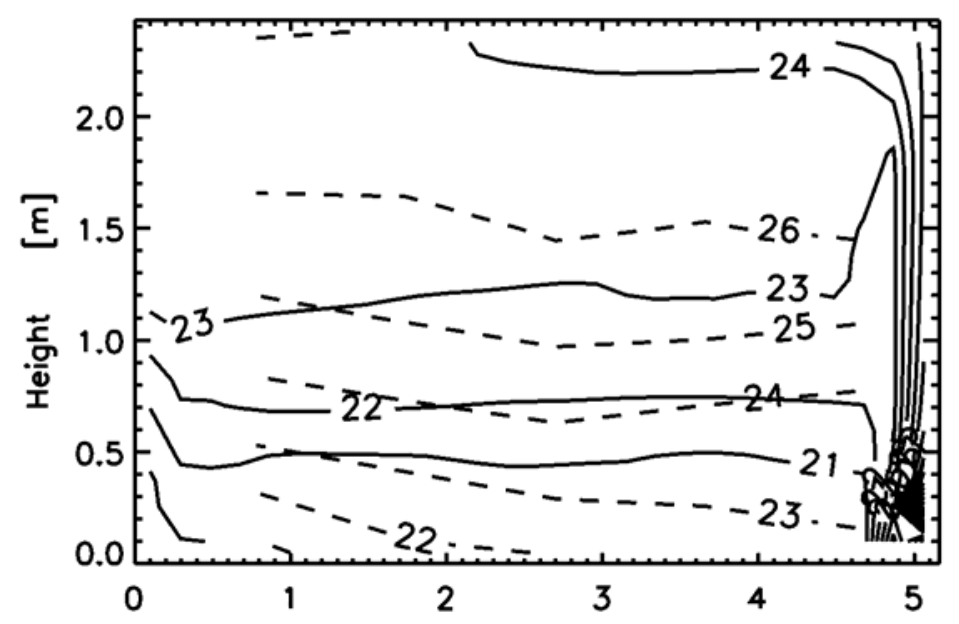

(b)

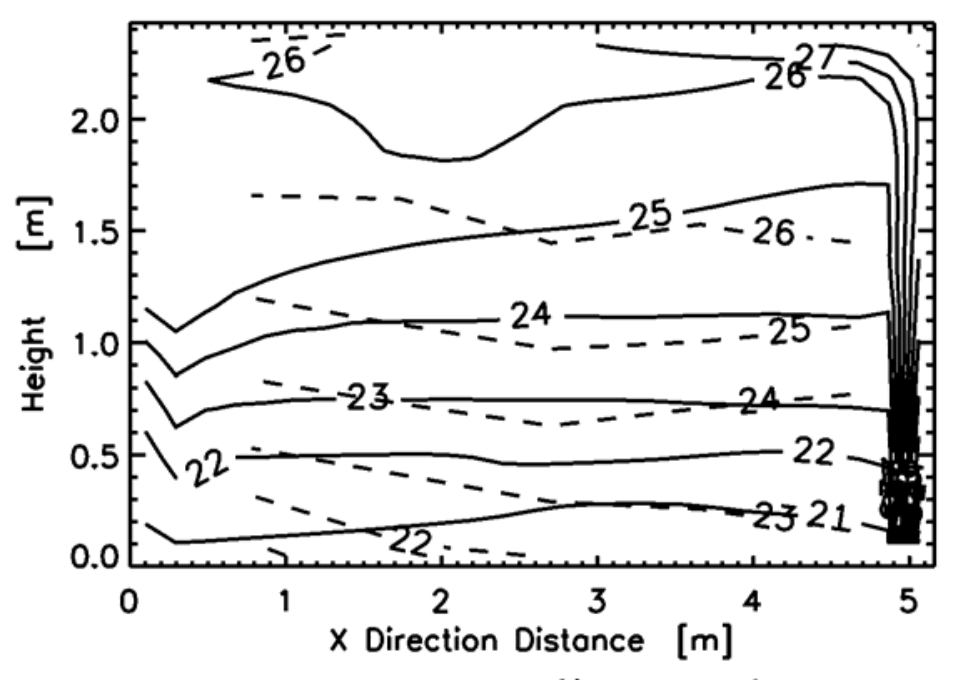

(c)

Figure 8 Momentum-zonal model results for case with a baseboard heater (a) 504-cell grid without blockages, (b)11880-cell grid with blockages, (c) 11880-cell grid without blockages 


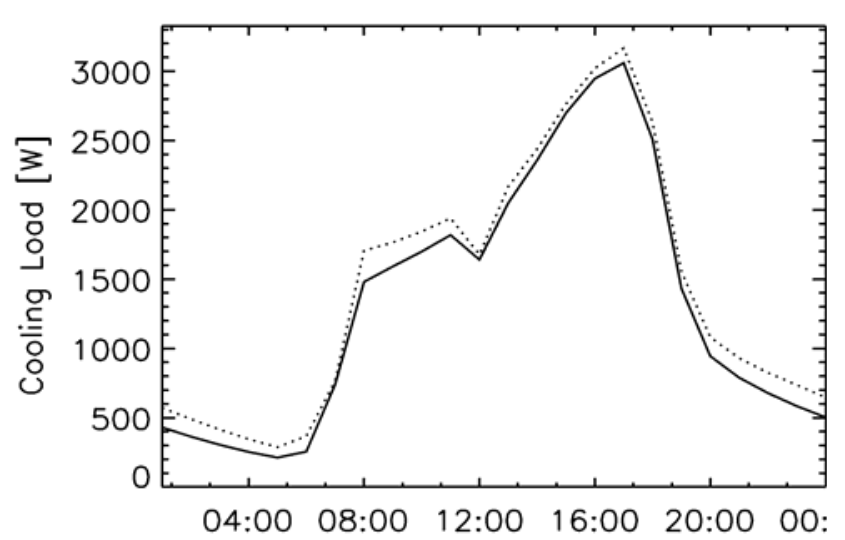

- mixing model

..... momentum model

(a)

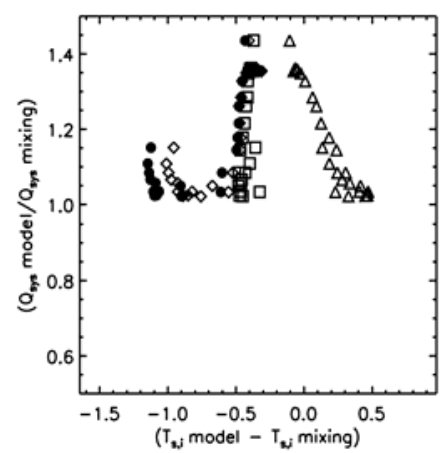

(b)

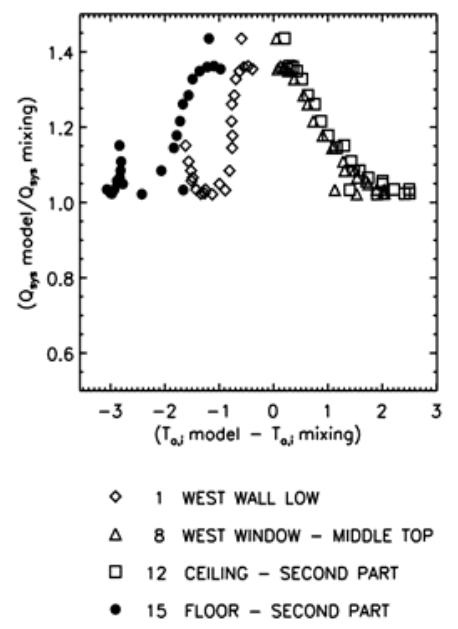

(c)

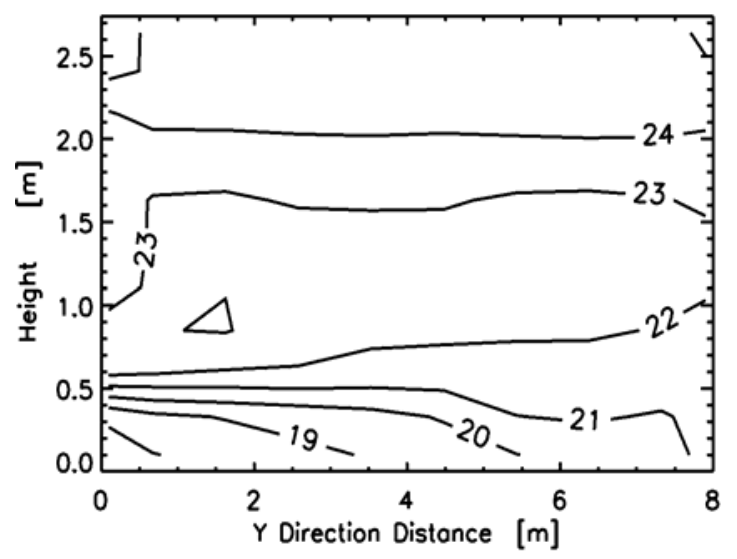

(e)

Figure 9 Cooling load results for office with displacement ventilation (a) cooling load, (b) change in $\dot{Q}_{s y s}$ versus $T_{s}(c)$ change in $\dot{Q}_{s y s}$ versus $T_{a}(d)$ computed flow field at 15:00 (e) computed air temperatures at 15:00 

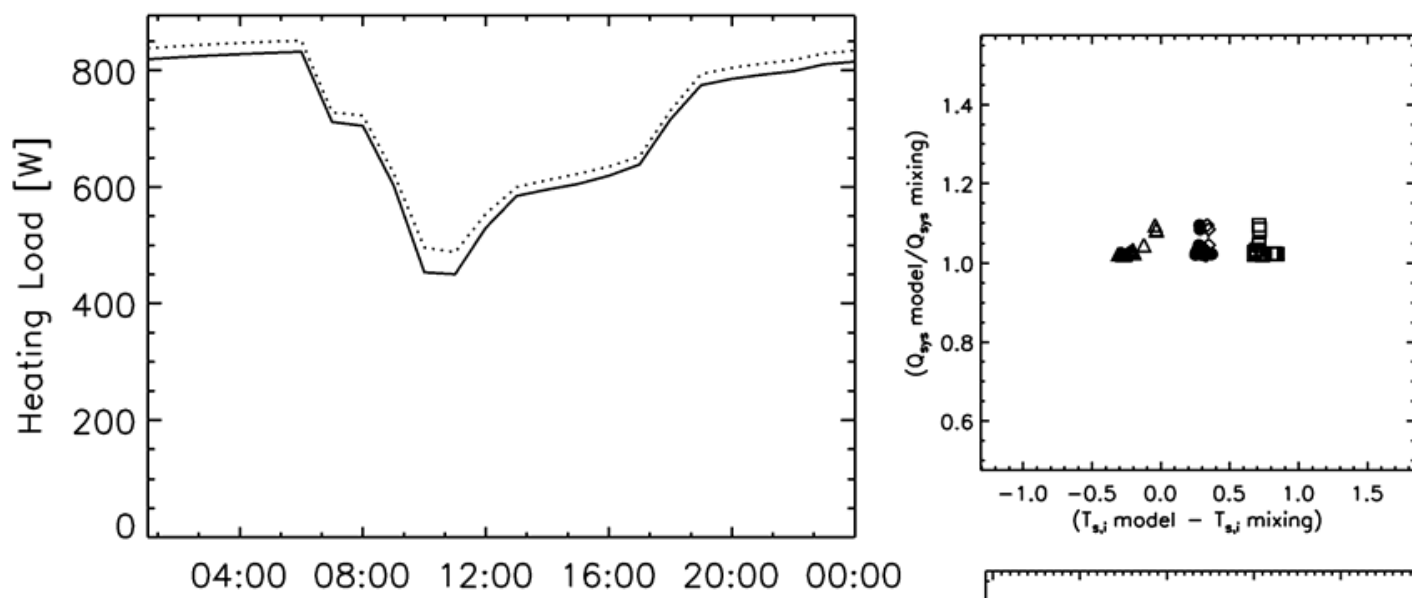

(b)

- mixing model

...... momentum model

(a)

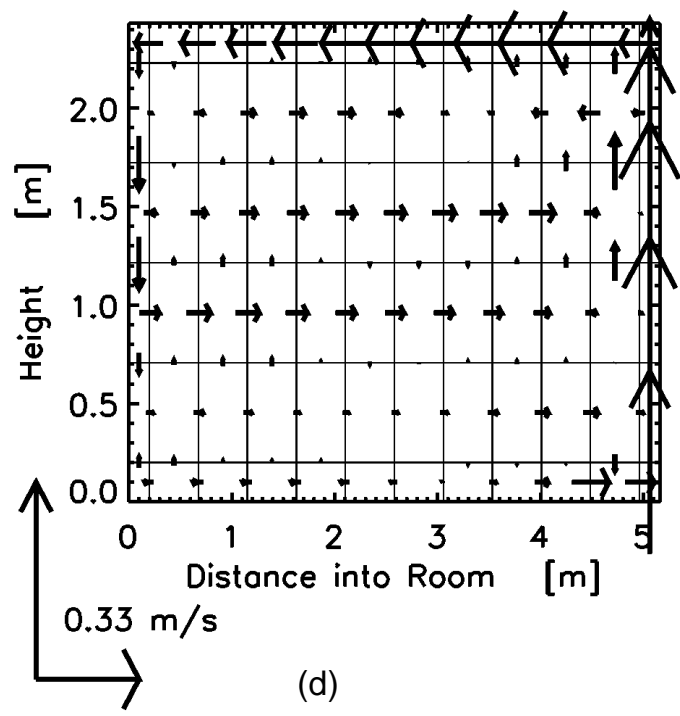

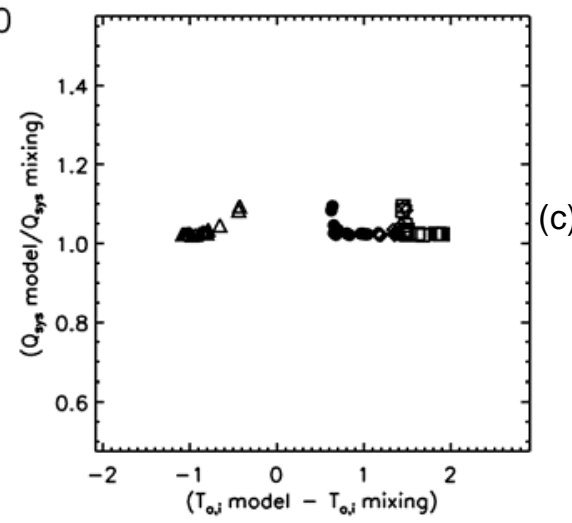

$\diamond 2$ CEILING - PART2

$\triangle 6$ FLOOR - PART2

口 8 EAST WALL - UNDER WINDOW

- 9 EAST WALL - WINDOW

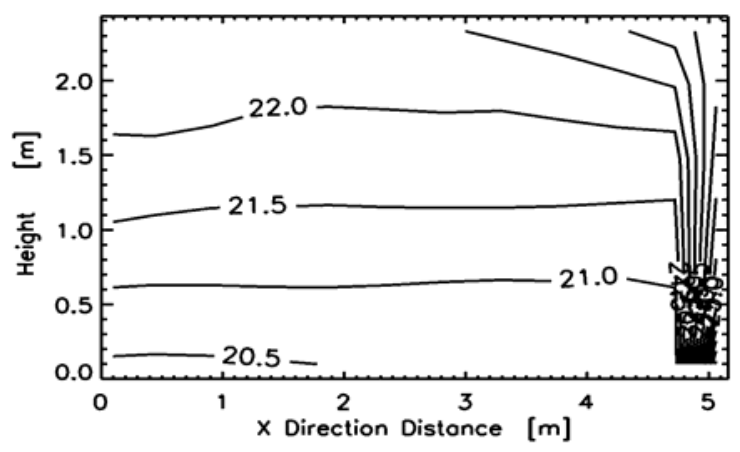

(e)

Figure 10 Heating load results for the case with a base-board heater (a) heating load, (b) change in $\dot{Q}_{s y s}$ versus $T_{s}\left(\right.$ c) change in $\dot{Q}_{s y s}$ versus $T_{a}(d)$ computed flow field at 9:00 am (e) computed air temperatures at 9:00am 